\title{
Sobre a melancolização do exílio
}

\author{
Alexei Conte Indursky*1 \\ Luiz Eduardo Prado de Oliveira*2
}

O presente artigo almeja oferecer algumas contribuições para a clínica psicanalítica do exílio junto a refugiados inseridos num contexto de reassentamento. Busca-se explorar, através de vinhetas de um caso clínico, operadores metapsicológicos que nos permitam melhor compreender as dinâmicas inconscientes presentes no processo de elaboração das violências do refúgio, sobretudo aquelas encontradas no processo de melancolização da experiência do exílio.

Palavras-chave: Exílio, trauma, melancolização, violências do exilio

${ }^{*}$ Université de Paris 7 - Denis Diderot 7 (Paris, França).

*2 Universidade de Bretagne Occidentale (Brest, França); Université de Paris 7 - Denis Diderot 7 (Paris, França). 


\section{Introdução}

Ao contrário do que secularmente se convencionou, o refúgio é por excelência um objeto ambivalente: verdadeira encarnação do pharmakos descrito por Derrida (1972), ele pode tanto salvar o sujeito do risco da morte quanto desencadear uma ruptura irreversível frente à terra deixada, condenando o sujeito a um desenraizamento de si mesmo. Longe de ser uma solução, a inquietante estranheza despertada por esse movimento de desterritorialização pode ser vivenciada, por alguns, como veneno da possibilidade de aceder ao desejo. Interessa-nos explorar como o testemunhar sobre a travessia do exílio instaura um processo de colagem aos eventos traumáticos e uma progressiva melancolização deste.

Trabalhamos com uma população de refugiados e seus familiares admitidos no Brasil através do programa de reassentamento do Alto Comissariado das Nações Unidas para Refugiados (ACNUR) e da Associação Padre Antônio Vieira (ASAV). O traço comum desse público é o fato de terem vivido um estado de exceção "provisoriamente permanente", no qual a vida é reduzida ao mero valor do corpo (Agamben, 2003) e a busca por sobrevivência se impõe ao psiquismo como lógica reinante. Se as experiências de separação e de perdas remetem à finitude, ao irrepresentável da morte e todo seu corolário de angústias, quando vividas em exílio elas se intensificam sobremaneira. Abre-se um espaço indeterminado na vida psíquica que a posteriori será vivido como uma ruptura que perfaz os elementos que "envelopam os lugares, os sons, os cheiros e as sensações de todos os tipos que constituem as impressões primeiras 
sobre as quais se estabelece a modulação do funcionamento pulsional" (Nathan, 1988, p. 96). A esse registro a psicanálise nomeou o originário. Ainda que este exerça desde sempre uma forte atração sobre o psiquismo, o sujeito não deve confrontá-lo diretamente sob o risco de ser invadido pelo irrepresentável do real. Podemos tão somente realizar relatos míticos ou fantasias sobre toda sorte de enigmas que se colocam sobre a origem, a sexualidade e a morte.

$\mathrm{Na}$ clínica do exílio, observamos que o encontro com o originário se produz em muitas ocasiões, dentre as quais sublinhamos notadamente a partida forçada. A impossibilidade de realizar rituais de adeus — não necessariamente religiosos ou sagrados, mas aqueles laicizados e particulares a cada comunidade - constitui-se como um traço distintivo do exilio frente $a$ outras migrações. Se nessas a fabricação de um projeto de vida é acompanhada de uma ritualística da partida, no exílio este tempo prévio é confiscado pela arbitrariedade da perseguição. $\mathrm{O}$ efeito dessa impossibilidade extrapola a perda de documentos e de objetos familiares: o exílio vem desestabilizar a continuidade da existência do psyché-soma (Winnicott, 1969). Sem embargo, não se trata de limitar a compreensão do trauma ao shock de um acontecimento excessivo e imprevisível, reputado traumático por si só. A complexidade de nosso terreno de investigação nos convida a revisitar a teoria do trauma a fim de pensar como os fatores exógenos da etiologia imbricam-se às dinâmicas inconscientes do sujeito.

Nessa perspectiva, as considerações clínicas de Ferenczi (1932/1985) demonstram sua relevância, uma vez que para o psicanalista húngaro o traumático não reside tão somente no ato do abuso sofrido pela criança, ou na fantasia edípica incestuosa como o quis a segunda teoria freudiana, mas no desmentido infligido pelo mundo adulto em reconhecer a vivência de excesso. O desmentido é trabalhado como um acontecimento sem autorização de ser vivido, ou, ainda, um episódio sem sujeito, cuja distinção entre interioridade e exterioridade é anulada pelo efeito de comoção. As consequências dessa desautorização repercutem diretamente ao nível egoico, na medida em que o episódio não deixa simplesmente de existir por que desmentido, mas sua permanência no psiquismo leva a uma espécie de enclave: sem autorização de entrar na transitividade do campo simbólico, um processo primitivo de defesa se instaura, a fim de fragmentar o registro do percebido e apartá-lo da consciência. $O$ resultado dessa operação pode levar desde a fragmentação do eu até a sua atomização, onde a identidade do sujeito ficará dividida em várias realidades conflitantes entre si: coexistindo, sem, todavia, interagirem. 


\section{ARTIGO}

Avançamos que, desde o processo de demanda de refúgio até a chegada no reassentamento, a dimensão dessa desautorização por parte do entorno sociopolítico-cultural cumpre uma função determinante na fragmentação e na atualização dos traumas vividos. A necessidade de responder ao Outro (estatal ou cultural) é muitas vezes injuntiva àqueles que não conseguem aceder aos episódios fragmentados de sua história e que devem provar a todo momento a verdade que suas palavras falham em atestar.

Com efeito, os recém-chegados tendem a se arrimar em um modo operatório, no qual precisam aprender tudo sobre como se restabelecer socialmente (papéis, educação, trabalho, saúde), mas fracassam em testemunhar de suas histórias. Uma ameaça de colapso invade o sujeito caso ele abandone a descrição estática e veja-se frente ao horror em busca de representação. Para além das políticas de integração propostas pelo programa do ACNUR, a experiência de elaboração desses episódios de violência, realizada numa cultura cujos códigos e interditos sociais se desconhece, é marcada pelo risco de costear o inefável e defrontar-se com o real não metabolizado de tais eventos (Prado de Oliveira, 1992). O acesso à habitação, ao mercado de trabalho e à capacitação linguística estão longe de oferecer uma garantia contra a eclosão sintomática observada durante os primeiros meses do reassentamento. Frente a isso, indagamos: qual o papel do socius no desencadeamento de um processo de luto no exílio?

Não raro, expressões como "luto impossível" ou "luto infinito" são empregadas na literatura psicanalítica para referir a elaboração impedida pelo horror totalitário (Waintranter, 2003). Frente à falta de tempo de realizar ritualísticas de adeus e a ausência de marcadores sociais nas sociedades acolhedoras, aventamos a hipótese de que os próprios episódios de perseguição e de fuga, em falta de representação, acabam por desorganizar os apoios narcísicos e identificatórios do sujeito, impedindo que a prova de realidade se realize. Muitos autores já sublinharam que para Freud (1915) o socius não ocupa nenhuma função no trabalho de luto (Allouch, 2004). No entanto, sabemos que tanto o luto (ainda que progressivamente contraído na tradição ocidental) quanto o exílio são fenômenos em que a coletividade cumpre um papel constitutivo, a saber, a fabricação de marcadores existenciais que atualizem no psiquismo a perda/separação do objeto no plano da realidade. Daí um estranho paradoxo de nossa atualidade: ambos fenômenos são socialmente reconhecidos como processos de transição incontornáveis pelos quais o indivíduo deve passar, entretanto, ambos são relegados a esferas do privado, senão do intrapsíquico. 
Não por acaso, a eclosão sintomática dá-se no momento no qual, interditado de retornar à terra deixada e convocado a recomeçar sua vida, o recém-chegado confronta-se com a dimensão do irreversível, despertando nele o tempo da perseguição e do assujeitamento vivido alhures. Segundo Vladmir Jankélévitch (1974/2007), o irreversível é a modalidade temporal por excelência, na medida em que ele interdita as idas e vindas no passado-presente-futuro. Se é verdade que o espaço se presta ao infinito ao deslocamento, a "irreversibilidade temporal impede o retorno de se dobrar exatamente sobre seu ponto de partida" (Jankélévitch, 1974/2007, p. 145). Ainda que na clandestinidade o sujeito possa deslocar-se de forma "desapercebida", nutrindo esperanças de retorno à terra deixada, uma vez que ele é admitido pelo ACNUR, ele se compromete em não retornar para o país de perseguição sob o risco de perder seu status. Frente ao irreversível de sua decisão forçada, o processo de ressignificação é interrompido, congelando o sujeito no 'tempo perdido' do exílio, verdadeiro pharmakós do refúgio.

Consideramos pertinente explorar, de acordo com as pontuações de Pierre Fédida (1999), uma matiz de reações ao luto situadas entre o luto normal e o melancólico, cuja gravitação entre o agir-maníaco e o agir-melancólico nos permitirá conceber as particularidades do luto no exílio. Ainda que o agir-melancólico seja reputado como inexistente, sustentamos que ele se enlaça ao tempo de uma culpabilidade inexpugnável, gravitando em torno do núcleo ausente do objeto, fato muitas vezes observado no exílio. Essa démarche nos abriria igualmente a possibilidade de pensar um processo gradual de melancolização deste, aquém de uma estruturação psicótica do sujeito. Levantamos assim a seguinte hipótese: se a terra deixada instala-se no psiquismo como ideia delirante diante da inacessibilidade de retorno à terra de origem, não estaríamos frente a um processo de colagem da pátria ao registro do originário?

\section{O colapso de Condolência}

Condolência, cinquenta anos, dirige-se à Polícia Federal onde fará o seu registro nacional de estrangeira. No entanto, em frente ao prédio ela é acometida por um mal súbito e desmaia. Em sua primeira entrevista, relata

${ }^{1}$ Tradução sugerida pelos autores.

Rev. Latinoam. Psicopat. $\overline{\text { Fund., São Paulo, }}$ 19(2), 242-258, jun. 2016 
que as coisas não estavam bem, que se preocupa muito com seus filhos e seu destino no Brasil. Fala da violência, do medo, da instabilidade aos quais os dois estavam expostos. Quando perguntada se fora por isso que desmaiara, confessa que não exatamente. Relata que pensava constantemente em 'quitar-se a vida', que uma culpa muito grande lhe abatia, seguida de enxaquecas colossais que a impediam de pensar. 'Não sei de onde vêm essas ideias, mais sei que não é certo pensá-las, e então eu desmaio'. Relata histórias fragmentadas, de tempos incendiários, de pessoas cujos nomes o analista ignora completamente.

Enquanto enfermeira e líder comunitária de sua cidade, Condolência havia denunciado o desaparecimento de um caminhão de suprimentos destinados à ONG em que trabalhava. Para seu infortúnio, o desvio havia sido executado por líderes de uma facção de guerrilheiros locais. Em represália à denúncia, fora sequestrada e mantida em cativeiro. O dia, ela refere, nunca lhe sairá da cabeça, 24 de novembro. No cativeiro foi torturada e violentada repetidas vezes pelos guerrilheiros que não a mataram somente por desleixo ou piedade. Aparentemente o carisma da líder comunitária os sensibilizara. Foi atirada nua em plena praça pública numa noite em que vários protestos se organizavam reivindicando o corpo desaparecido de Condolência. Humilhada, esfolada, violentada, decidira denunciar as pessoas que reconhecera em cativeiro. 'Todos caíram em cascata, um entregou o outro e logo decidiram ir atrás de mim novamente'. Daí o refúgio, realizado na penumbra da noite num caminhão, tal qual uma mercadoria clandestinamente desviada. Ela chora copiosamente. A denúncia fora o pior erro de sua vida.

O colapso de Condolência se dá precisamente no momento em que o pior parece já haver passado. Não por acaso, isso se dá quando ela está prestes a entrar na formalidade de uma nova cultura. Sabemos que não é suficiente falar para estar na lógica do discurso; é preciso endereçar-se a alguém, encontrar um ponto de ancoragem no outro. Em casos de assujeitamento extremo ao torturador um silêncio parece estabelecer-se de forma definitiva entre a vivência humilhante e a possibilidade de narrá-la. A captura da dimensão da alteridade abole o Outro enquanto "álibi da verdade" do sujeito (Lacan, 1957-1958/1999, p. 29), cujos efeitos repercutem em uma não separação entre o fato de 'ser vítima de' e 'ser sua vítima'. A presença do pronome possessivo indica a extensão do laço inconsciente de assujeitamento estabelecido pelo algoz (Indursky, 2013).

Ao longo de algumas consultas irregulares Condolência demonstra a impossibilidade de investir em qualquer objeto de sua atualidade. 
Primeiramente seus filhos que aprendem rapidamente o português e tornam-se estrangeiros a seus olhos; em seguida, o comerciante que the convida para sair; finalmente, a figura do analista que se torna um potencial violador. Em todas as situações a cena da sedução é capturada rapidamente pelo registro do traumático. Cabe lembrar que frente à frustração crescente a paciente procede a inúmeros pedidos dirigidos ao analista e aos agentes do programa de reassentamento: trazer seu neto da Colômbia, colocar seus filhos em tratamento, trocar de casa, mudar o horário das sessões. Assim, a raiva, e por vezes a cólera, são as únicas formas que encontra para destruir qualquer tipo de nova excitação psíquica que a coloque à prova de sua nova situação. Nesse limiar são as imagens de violência e de sua pátria que a invadem sistematicamente, não como recordações, mas como ataque do real não metabolizado de uma constelação de objetos - insubstituíveis, por certo - mas que não podem ser esquecidos, pois sempre atuantes em seu psiquismo. Ao cabo desses momentos, o que lhe resta é a recriminação do pior erro de sua vida e a dor.

\section{Da dolência ao sofrimento: travessia do luto}

Passados 11 anos de "Luto e melancolia" Freud se pergunta "quando a separação de objeto produz angústia, quando produz luto e quando produz somente dor?" (Freud, 1926/1981b, p. 2881). Questão que nos remete ao enlace entre trauma e luto, cujas nuances ele deixa inexploradas em 1915, e que o caso de Condolência instiga a revisitá-las. Vejamos o que o autor responde: "A passagem da dor física à dor psíquica corresponde à passagem do investimento narcísico ao investimento de objeto" (p. 2881). Segundo o modelo apresentado em 1915, essa passagem do investimento narcísico (segundo tempo do luto) ao reinvestimento de objeto (terceiro tempo) revela o circuito de tradução da dor corporal em sofrimento psíquico. Essa operação realizada "traço por traço" da constelação de investimentos ligados ao objeto possibilitaria uma espécie de transcrição da dobra vergonhosa 'eu sou a vítima do pior erro da minha vida' a 'eu escolhi não me calar sob o preço de me exilar'. Travessia em que o registro da dor outrora aglutinada pela autorrecriminação moral pode traduzir-se em sofrimento psíquico e o objeto pode finalmente ser perdido.

Concebemos assim a importância dessa Con-dolencia, enquanto posição através da qual a paciente se oferece ao olhar do Outro, para reconhecer a 


\section{ARTIGO}

si mesma a partir da fragmentação sofrida no eu. No entanto, é igualmente através dessa posição que ela consegue 'descompletar' o outro, que se torna um potencial violador por obra do acaso traumático. Sustentamos que esse traço transferencial não pode ser limitado a um caso específico: sua insistência em nossa experiência demonstra que é justamente aí que se encontram as dificuldades advindas da diferença cultural e das diferentes posições de inscrição do Outro da cultura. A ameaça sentida junto à comunidade receptora se atualiza pelas vias de uma oferta sem reciprocidade possível, pois advinda de uma solicitação que não demanda, visto que demandar implica colocar-se enquanto sujeito faltante: todos os pedidos realizados pela paciente caíam também 'em cascata', na medida em que demandavam investimentos impossíveis de serem sustentados. Entre um estado de sobrevivência autoconservativo e o re-acesso à função metaforizante da linguagem, não deveríamos nos perguntar: "é possível sair de uma situação traumática de outra forma senão pela travessia de uma situação totalitária na transferência?"2 (Borgel, 1999, p. 62).

Observamos, assim, que frente à impossibilidade de tradução da dor física ao sofrimento psíquico, o sujeito entrega-se a um procedimento de comemoração do traumático atestando a temporalidade cronificada, na qual o tempo atual é o tempo infinito da dor experimentada pelo sujeito.

\section{O des-aniversário de morte: o encontro perdido com o real}

Após um par de meses de consultas, a paciente queixa-se por longos minutos dos filhos até chegar ao ponto fatídico. Estávamos a uma semana do dia 24 de novembro, o dia de seu sequestro. $\mathrm{O}$ analista reage na hora com uma exclamação de surpresa, pedindo que conte o que lhe vem à cabeça. 'Pois... é o dia do meu aniversário, mas não de nascimento'. Passa a narrar então o dia 24, desde a preparação para um piquenique na parte da manhã até o final do dia com a casa cheia de familiares. A narrativa é marcada pelo registro do sensorial e dos afetos até então apartados de seu discurso. É uma descrição totalmente diferente daquela que havia feito na primeira entrevista. No lugar da tortura e da humilhação, afloram todos os elementos que constituíam sua

${ }^{2}$ Tradução sugerida pelos autores.

Rev. Latinoam. Psicopat. Fund., São Paulo, 19 (2), 242-258, jun. 2016 
posição no laço social e que lhe seriam arrancados, tal qual seus dentes na tortura, deflagrando a extensão da ruptura do exílio. O cair do sol demarcava igualmente essa queda, a perda desses incontáveis objetos, as galletas, as piñas, as montanhas. Todas essas lembranças, intervém o analista, demonstravam sua vontade de viver e seu trabalho em análise era poder justamente reconstruí-los com os ingredientes daqui. Ela olha rindo e fala, 'mas que trabalho sagrado!'.

Essa foi a última sessão de Condolência. Na véspera de 24 de novembro ela não compareceu à sessão, tampouco retornou as ligações. Passado um mês, ela decide, apesar de todas as recomendações, retornar à Colômbia. Consideramos que a contribuição mais distintiva da psicanálise à clínica do exílio aparece nessa dimensão do 'encontro perdido' da repetição traumática: ao contrário da compreensão implícita à noção de estresse pós-traumático, o trauma não reside tão somente no episódio excessivo por si só, mas implica um segundo momento de 'comemoração' do trauma no qual o gozo mortífero entranha-se a essa parte caída de si, a qual não se consegue abandonar. Uma das últimas frases que a paciente endereça a seu analista - mas que trabalho sagrado! - sugere a resposta inconsciente engendrada por ela, frente à

250 exigência do trabalho de luto. Ao invés de caracterizar essa reação mortífera como um luto impossível, interessa-nos interrogar como essa sacralização de uma parte ausente de si responde a uma confusão entre a terra perdida e o originário.

\section{Melancolização do exílio}

Ante à possibilidade de narrar em sua língua de origem os episódios anteriores ao exílio, observamos uma espécie de revés no processo analítico suscitado pela dimensão não pacificadora que a reentrada do sujeito na linguagem pode acarretar. Esse revés não nos sugeriria os riscos inerentes à tentativa de testemunhar para si o terror vivido, visto que esta implica fazer "eco imaginário" às rebarbas de real, percepções fragmentadas e significações desmentidas pela efração do trauma? Esse fenômeno imaginário suscitado brevemente por Jacques Lacan (1966/1998) e revisitado por Geneviève Morel (2001) nos interessa aqui, visto que ele se distingue das rememorações de ordem neurótica, aproximando-se das reminiscências do real invadindo o psiquismo. Lacan sugere pensá-lo como uma "resposta a um ponto da realidade que pertence ao limite onde ele foi suprimido do simbólico" (Lacan, 


\section{ARTIGO}

1966/1998, p. 393). O processo analítico tocaria nessa borda entre o real e o simbólico, fazendo emergir o irrepresentável sob desenvolvimento de angústia, inclusive de passagens ao ato. Nessa perspectiva Geneviève Morel (2001) propõe que essas imagens quase alucinatórias, situadas no hiato entre o real e o simbólico, invadem o sistema perceptivo e ganham um poder de atração muito forte sobre o psiquismo, suscitando uma colagem do sujeito a estas, que passarão a ser investidas como lugar da origem perdido.

Explorando o processo testemunhal de Primo Levi ao longo dos anos, a autora sublinha uma espécie de exaustão da memória, na qual Levi não tem mais acesso à sua experiência senão a partir de seus escritos, objetos ou amigos; espécie de memória artificial ou de prótese que se interpõe entre ele e sua experiência e que, todavia, instala uma dúvida constante sobre que parte da catástrofe ainda o habita. Entre o vazio de memória e a tentativa de fazer os retratos de todos os desaparecidos dos campos, dando-lhes um pretenso reconhecimento e posição no laço social, Levi teria se engajado em um trabalho infinito, verdadeiro processo de melancolização sob a sombra de um duplo de identidade mórbida: o mulçumano que 'tocara o fundo' e nunca voltara para testemunhar. ${ }^{3}$ É sob essa lógica que seu suposto suicídio encontraria uma explicação.

Nessa mesma via, Borgel (1999) se refere à conservação das cenas traumáticas através da literalidade do testemunho: o relato do sujeito permanecerá sempre gravitando em torno de um núcleo mórbido e ausente, para valer-se como uma prova última sobre o evento do qual ele é a 'única' testemunha. Isolamento e solidão de um evento que exaure a potência metafórica da linguagem. Importante constatar aqui que, à oposição das efemérides simbólicas dos golpes de Estado promovidas nas respectivas datas dos putschs (onde a comunidade pode comemorar conjuntamente o Nunca mais! próprio à fratria totêmica), o des-aniversário de morte de Condolência se constitui como o exemplo paroxístico de compulsão à repetição de uma dor impossível de

\footnotetext{
${ }^{3}$ Importante sublinhar aqui que essa leitura sobre as causas melancólicas do suposto suicídio de Levi, centradas na figura do muçulmano como um duplo é contestada por diversos autores. Nós citamos aqui a título de contraponto a excelente biografia de Phillipe Mesnard (2011), Primo Levi. Le passage d'un témoin, na qual ele aborda a figura de Wanda, uma das mulheres no campo de quem Levi guarda uma forte admiração, mas também uma das principais fontes de sofrimento, confessada apenas em seus diários íntimos analisados pelo autor.
} 
compartilhar e, por conseguinte, impossível de esquecer. Se as efemérides de des-comemoração opõem-se ao esquecimento como compromisso simbólico de memória face ao terror, o des-aniversário de morte, como concebido aqui, permanece marcado pelo pathos de ser o bastião solitário de uma memória individual e não coletivizada. Trabalho de Sísifo que, a exemplo de alguns sobreviventes das ditaduras latino-americanas, pode vir a estabelecer um pacto eterno consigo mesmo ou com um ente desaparecido, no qual a afirmação da singularidade do episódio vivido 'você jamais entenderá o que passei' confunde-se com sua sacralização 'é impossível comunicar a uma pessoa o que vivi' (Agamben, 2003, p. 35).

Após experimentar episódios crônicos de retocolites, Condolência consulta um médico e sai de lá (auto)diagnosticada com um câncer no útero. Seu ex-analista é informado dessa situação por acaso, quando visitava o escritório da ASAV e ela encontrava-se lá também. Após insistir em falar a sós, ela lhe confia a necessidade imperativa de retornar para Colômbia para salvar sua vida, dado o custo do tratamento no Brasil. A obstinação em afirmar que tinha um câncer, recusando-se a apresentar qualquer exame que confirmasse o diagnóstico, fez com que fosse proposta uma nova consulta para que pudesse falar 252 sobre o retorno iminente. Proposição a qual ela aceita não sem propor que o analista fosse à sua casa visitá-la. Frente à negativa, ela ri e complementa: 'agora é o momento em que você devia me mandar aos diabos!'. O suposto câncer vem selar metonimicamente a sacralização do episódio doloroso, cuja cura passa por um retorno que, doravante, será investido enquanto messiânico.

Essa guinada imprevista do caso de Condolência nutriu certamente sentimentos de traição na equipe de reassentamento, bem como a hipótese de uma impostura perversa, tendo em vista as estratégias instauradas para se levantar fundos para sua viagem. Condolência passa semanas contando a história trágica de seu exílio à vizinhança, ao fim das quais consegue um montante considerável de dinheiro para todos retornarem. Concomitantemente, cai doente inúmeras vezes: cãimbras, paralisias nas pernas, enxaquecas, enfim, todo um repertório de impedimentos que retornam sobre seu corpo a fim de confirmar inconscientemente sua condição de doente. Não por acaso, o corpo toma aqui a função de último refúgio do sujeito desenraizado, enquanto porta-voz da dor que não passa pela via simbólica da expressão sintomática. Aquilo que se convencionou chamar de ganho secundário da fuga na doença toma aqui o protagonismo na doença somática.

Retomamos assim nossa hipótese: se a terra deixada instala-se no psiquismo como ideia delirante diante da inacessibilidade de retorno à terra de 


\section{ARTIGO}

origem, não estaríamos frente a um processo de colagem da pátria ao registro do originário? Interrogamo-nos se esses 'ecos imaginários' do real suscitados a partir do engajamento no tratamento não produziram uma gradual colagem ao originário, na qual a principal modalidade de investimento não é regida por Eros, mas pela positivação do mortífero. Ali onde o valor simbólico da terra é cortado pela ruptura do exílio, a possibilidade de investimento nos objetos da nova atualidade é constantemente descosturada pela pulsão de morte. Frente ao vazio identificatório causado pela ação desses ecos imaginários, o retorno messiânico e curador de Condolência seria um primeiro passo de metaforização, ainda que realizado através de um delírio curador das perdas e separações do exílio.

É a partir da oscilação estruturalmente isomórfica entre os polos do agir maníaco e do agir melancólico que situamos o movimento pulsional apresentado ao longo do exílio de Condolência. Após uma primeira fase maníaca e operatória, na qual as respostas oferecidas por ela revelavam-se 'adaptadas' ao contexto atual, observamos que seu colapso subjetivo é acompanhado por um gradual processo de melancolização frente à situação analítica, que, por sua vez, cede espaço a um novo momento maníaco, perfeitamente adaptado ao retorno messiânico. Nesse sentido, não poderíamos negligenciar que o agir melancólico, longe de ser inexistente, materializa-se através da positivação do mortífero na comemoração de um des-aniversário traumático, cuja celebração coloca em ato a perseguição exercida pela ausência do objeto. Em seu novo acesso ao agir maníaco, sua execução visa garantir, em última instância, a realização do agir melancólico — retorno ao estado de plenitude perdida na Colômbia - sempre referida em seu núcleo extático de des-aniversário.

Se Morel (2001) explora sua hipótese de melancolização notadamente a partir do fracasso simbólico das palavras contaminadas pela atração imaginária das imagens de terror, Olivier Douville (2003) sublinha que o trabalho de luto do exílio deve passar pela construção de um espaço de memorialização dos episódios de violência no exílio. Operação que perpassa os registros do real, imaginário e simbólico a fim de restabelecer uma fronteira não tóxica entre estes. Não se trataria ainda da elaboração do luto, mas de um gesto prévio de criação de uma sepultura para inumar os eventos traumáticos. Como nos lembra Marcelo Viñar (1993) é preciso que se deixe morrer algo de si que permanecerá como irrecuperável — porque inumado - a fim de se preservar aquilo que com o tempo se despontará como o mais importante da experiência. É através dessa reconstrução de fronteiras que se 
contorna o irrepresentável, conferindo-lhe um lugar, para que dele se guarde um traço intraduzível, de inadequação, de inconformidade com o vivido. Menos para empreender um trabalho infinito de comemoração do horror, mais para que sempre haja um resto: que 'tudo nunca seja dito' - inflexão à orientação primeira da psicanálise - é uma das formas para que o suicídio e o isolacionismo não se tornem a única via de dar conta do sofrimento irreparável.

Nessa perspectiva, a melancolização do exílio de Condolência pode ser lida através desse gesto-colagem, uma vez que o regresso marca a impossibilidade de identificar-se aos objetos de sua atualidade. No entanto, seu retorno messiânico demarca igualmente uma resposta delirante de construção de uma sepultura à data de 24 de novembro, com todos os riscos mortíferos ali implicados. Tentativa primitiva de simbolização do evento fatídico dentro da coletividade que o engendrou, ao invés da solidão que o exílio the impingia. Assim, o caso de Condolência põe em xeque a concepção individualista do trabalho de luto em Freud. Ele aponta para a importância que o entorno cultural confere à fabricação de mediadores que restituam o sujeito enquanto protagonista da cena desmentida, em sua tarefa de reconstrução dos sentidos

254 da realidade, como menciona Ferenczi (1932/1985). Frente à fragmentação do eu, o luto deverá reinscrever o sujeito na ordem simbólica de uma cultura, sem o que toda excitação provinda da atualidade do sujeito remete-o à vacuidade da terra perdida, suscitando um processo de colagem gradual às imagens desta.

\section{Referências}

Agamben, G. (2003). Ce qui reste d'Auschwitz. Petite Bibliothèque Payot. Paris: Rivages poches.

Allouch, J. (2004). Erótica do luto. No tempo da morte seca. Rio de Janeiro: Cia. de Freud.

Borgel, M. (1999). Témoignages. In N. Zaltzman et al., La résistance de l'humain. Paris: P.U.F.

Derrida, J. (1972). La pharmacie de Platon. In La dissémination. Points/Essais. Paris: Le Seuil.

Douville, O. (2003/1). Du choc au trauma... il y a plus d'un temps. Figures de la psychanalyse, 8, 93-96.

Fédida, P. (1999). Depressão. São Paulo: Escuta. 


\section{ARTIGO}

Ferenczi (1985). Journal Clinique. Janvier-Octobre. Paris: Payot. (Trabalho original publicado em 1932).]

Ferenczi, S. (2010). Psychanalyse des névroses de guerre. In Sur les névroses de guerre. Paris: Petite Bibliothèque Payot. (Trabalho original publicado em 1918).

Freud, S. (1981a). Luto e melancolia. In Euvre complètes (v. II). Madrid: Nueva Biblioteca, Lopez-Ballesteros y de Torres. (Trabalho original publicado em 1915).

Freud, S. (1981b). Inibition, sintoma et angustia. In Euvre complètes (v. III). Madrid: Nueva Biblioteca, Lopez-Ballesteros y de Torres. (Trabalho original publicado em 1926).

Jankélévicht, V. (2007). L'irréversible et la nostalgie. Paris: Flammarion. (Trabalho original publicado em 1974).

Indursky, A. (2013). Encruzilhadas da demanda: a clínica junto a sujeitos vítimas de violência de Estado. Sig: revista e psicanálise. 1(2), 67-75.

Lacan, J. (1998). Resposta ao comentário de Jean Hyppolite sobre a "Verneinung" de Freud. In Escritos. Rio de Janeiro: Jorge Zahar. (Trabalho original publicado em 1966).

Lacan, J. (1999). Le séminaire. Livre V. Les formations de l'inconscient. Rio de Janeiro: Zahar. (Trabalho original publicado em 1957-1958).

Mesnard, P. (2011). Primo Levi. Le passage d'un témoin. Paris: Fayad.

Morel, G. (2001). La mélancolisation du témoin: l'impuissance des mots, le pouvoir des images. Plataform 2_Documenta 11, New-Dehli, 8 Mai 2001. Texto não publicado.

Nathan, T. (1988). La migration des âmes. Le temps interrompu. Grenoble: La Pensée Sauvage.

Prado de Oliveira, L. (1992). De la torture, de l'exil et du génocide. Dialogues recherches cliniques et sociologiques sur le couple et la famille, 3, p. 88-102. [Link]

Winnicott, D. (1969). De la pédiatrie à la psychanalyse. Paris: Petite Bibliothèque Payot.

Waintranter, R. (2003). Sortir du génocide. Témoignage et survivance. Paris: Petite Bibliothèque Payot.

Viñar, M. (1993). Fracturas de memoria. Crónicas para una memoria por venir. Montevideo: Ediciones Trilice. 


\section{Resumos}

(On the melacholization of exile)

This paper aims to contribute to the psychoanalytic clinic of exile concerning refugees in the specific context of resettlement. We aim to develop, through excerpts from a clinical case, metapsychological keys that allow us to better understand the unconscious dynamics figuring in the elaboration process of violence in the refugemainly of the violence found in the melancholization of the exile experience.

Key words: Exile, trauma, melacholization, violence in the refuge

(À propos de la mélancolisation de l'exil)

Cet article vise à apporter des contributions à la clinique psychanalytique de l'exil auprès des réfugiés dans le contexte d'une politique de placement. On cherche à exploiter, par le biais de vignettes cliniques, les opérateurs métapsychologiques qui nous permettent de mieux comprendre les dynamiques inconscientes présentes dans le processus d'élaboration des violences subies, en particulier celles que l'on retrouve dans le processus de mélancolisation de l'expérience de l'exil.

Mots clés: Exil, traumatisme, mélancolisation, violences du refuge

(Sobre la melacolización del exilio)

El presente artículo busca ofrecer algunas contribuciones a la clínica psicoanalítica del exilio junto a los recién llegados admitidos en el contexto específico de una política de reasentamiento. Buscamos explorar, a través de viñetas de un caso clínico, operadores metapsicológicos que permitan comprender las dinámicas inconscientes presentes en el proceso de elaboración de las violencias del exilio, sobre todo, aquellas encontradas en el proceso de melancolización de la experiencia del exilio.

Palabras clave: Exilio, trauma, melancolización, violencias del exilio

(Über die Melancholisierung des Exils)

Dieser Artikel ist einen Beitrag zur psychoanalytischen Klinik des Exils von Flüchtlingen im Kontext der Umsiedlung. In diesem Zusammenhang analysieren wir einen klinischen Fall, um die metapsychologischen Operatoren zu erforschen und dabei die unbewusste Dynamik des Verarbeitungsprozesses der während der Flucht erlebten Gewalt besser zu verstehen, speziell diejenige des Melancholisierungsprozesses der Exilerfahrung.

Schlüsselwörter: Exil, Trauma, Melancholisierung, Gewalt der Flucht 


\section{ARTIGO}

流放忧郁症

本文尝试对被重新安置的难民的忧郁症进行临床精神分析。通过对一个临 床案例的解析, 研究病人宏观心理因子, 我们能够了解病人的动态的无意识状 态, 作为难民, 在流亡过程中使用暴力和被暴力, 也会因为流亡和流亡生活而 产生的忧郁症。

关键词: 流亡, 创伤, 忧郁症化, 难民暴力。

Citação/Citation: Indursky, A. C., Prado de Oliveira, L. E. (2016, junho). Sobre a melancolização do exílio. Revista Latinoamericana de Psicopatologia Fundamental, 19(2), 242-258.

Editores do artigo/Editors: Prof. Dr. Manoel Tosta Berlinck e Profa. Dra. Sonia Leite

Recebido/Received: 4.3.2015/ 3.4.2015 Aceito/Accepted: 19.5.2015 / 5.19.2015

Copyright: (C) 2009 Associação Universitária de Pesquisa em Psicopatologia Fundamental/ University Association for Research in Fundamental Psychopathology. Este é um artigo de livre acesso, que permite uso irrestrito, distribuição e reprodução em qualquer meio, desde que o autor e a fonte sejam citados / This is an open-access article, which permits unrestricted use, distribution, and reproduction in any medium, provided the original authors and sources are credited. 
Financiamento/Funding: Os autores declaram não ter sido financiados ou apoiados / The authors have no support or funding to report.

Conflito de interesses/Conflict of interest: Os autores declaram que não há conflito de interesses / The authors have no conflict of interest to declare.

\section{Alexei Conte Indursky}

Mestre e Doutorando em Psicanálise e Psicopatologia no Centre de recherches en psychanalyse, médecine et sociétés (CRPMS) École doctorale «Recherches en psychanalyse et psychopathologie», Université de Paris 7 - Denis Diderot 7 (Paris, França).

Rua Correia de Lima, 1421 - casa 2

90850-250 Porto Alegre, RS, Br

leco.indursky@globo.com

\section{Luiz Eduardo Prado de Oliveira}

Professor emérito de psicopatologia, Universidade de Bretagne Occidentale; Diretor de pesquisa do Centre de recherches en psychanalyse, médecine et sociétés (CRPMS); École doutoral "Recherches en psychanalyse", Université de Paris 7 - Denis Diderot (Paris, França).

107, Rue Mouffetard

75005 Paris, França

pradodeoliveira@free.fr

This is an open-access article, which permits unrestricted use, distribution,

(cc) BY-NC and reproduction in any medium for non-commercial purposes provided the original authors and sources are credited. 